ARTICLE

https://doi.org/10.1038/s41467-019-14074-5

\title{
Midwinter Arctic leads form and dissipate low clouds
}

\author{
Xia Li (iD ${ }^{1 \star}$, Steven K. Krueger ${ }^{1}$, Courtenay Strong (10 ${ }^{1}$, Gerald G. Mace ${ }^{1}$ \& Sally Benson (1D ${ }^{1}$
}

Leads are a key feature of the Arctic ice pack during the winter owing to their substantial contribution to the surface energy balance. According to the present understanding, enhanced heat and moisture fluxes from high lead concentrations tend to produce more boundary layer clouds. However, described here in our composite analyses of diverse surface- and satellite-based observations, we find that abundant boundary layer clouds are associated with low lead flux periods, while fewer boundary layer clouds are observed for high lead flux periods. Motivated by these counterintuitive results, we conducted threedimensional cloud-resolving simulations to investigate the underlying physics. We find that newly frozen leads with large sensible heat flux but low latent heat flux tend to dissipate low clouds. This finding indicates that the observed high lead fractions likely consist of mostly newly frozen leads that reduce any pre-existing low-level cloudiness, which in turn decreases downwelling infrared flux and accelerates the freezing of sea ice.

\footnotetext{
${ }^{1}$ Department of Atmospheric Sciences, University of Utah, 135 S 1460 E, Salt Lake City, UT 84112-0102, USA. *email: xia.li@utah.edu
} 
eads are quasi-linear openings within the interior of the polar ice pack, where the ocean is exposed directly to the atmosphere ${ }^{1}$. Leads range in width from several meters to tens of kilometers with narrow leads most abundant and in length from hundreds of meters to hundreds of kilometers (Supplementary Fig. 1). Due to the extreme air-water temperature contrast $\left(20-40^{\circ} \mathrm{C}\right)$, turbulent heat fluxes over leads can be two orders of magnitude larger than over the ice surface in winter ${ }^{2}$. While winter leads climatically cover $2-3 \%$ of the total surface area of the central Arctic and 6-9\% of the Arctic peripheral seas (Supplementary Figs. 2 and 3), these large heat fluxes dominate the wintertime heat budget of the Arctic boundary layer ${ }^{2-5}$. Moreover, leads are also a source of moisture which can induce boundary layer clouds locally ${ }^{6}$. The presence of these clouds has the potential to extend the thermodynamic impact of leads over large-scale regions through their vertical and horizontal development $^{7,8}$ as well as the enhanced downward infrared radiative flux $^{9-11}$. Boundary layer cloud cover also exerts a significant impact on the equilibrium sea ice thickness ${ }^{10}$, which is a key indicator of changes in Arctic heat transport ${ }^{4}$. Therefore, lowlevel clouds significantly influence how leads impact the Arctic surface energy balance.

Correctly understanding the lead-modified surface energy budget is important. However, accurate determination of wintertime low-level cloud fraction over the Arctic Ocean from satellites is still a challenge owing to the presence of the underlying leads and sea ice, and the polar night. Previous observations demonstrate a replacement of thick, multi-year ice by thin, firstyear ice ${ }^{12}$, a gradual acceleration in sea ice drift and wind stress ${ }^{13}$, increases in sea ice mean strain rate and the associated deformation rate ${ }^{14}$, and a marked widening of the marginal ice zone ${ }^{15}$ in the Arctic. All these observational findings suggest an increasing presence of Arctic leads in the climate system, which motivates a study to understand associated changes in boundary layer clouds and thus estimate the associated large-scale heat balance in response to changes in lead fraction. As a first step in this direction, here we explore the potential influences that leads have on boundary layer clouds in the wintertime Arctic.

Due to the limitation of observations in the Arctic, previous studies have mostly used model simulations to examine the clouds or convection induced by a single lead in idealized or simplified situations ${ }^{8,11,16-23}$. Few of those studies investigated the low-level clouds over a realistic ensemble of leads. In this study, diverse ground- and satellite-based observed records of the Arctic system near Barrow, Alaska, are combined with a threedimensional cloud-resolving model to examine the effects of leads on boundary layer clouds. Based on the observations, we first attempt to establish a statistical relationship between the largescale sensible heat flux due to leads and low-level cloud frequency. Furthermore, a cloud-resolving model is used to better understand the underlying physics of the observed lead-low cloud associations. We find low-level cloud occurrence frequency decreases with increasing large-scale lead flux and show that it is induced by the recently frozen leads, which constitute a majority of the satellite-detected lead fraction.

\section{Results}

Observed lead-low cloud associations. Previous observational analysis $^{24}$ shows that low-level clouds predominate at Barrow throughout the year, especially during fall and winter. In this study, we investigate the effects of leads on low-level clouds at a local scale, offshore within $200 \mathrm{~km}$ of the Barrow site (as indicated by the black semicircle in Fig. 1b, d) over the period 2008-2011 (see Methods). Profiles of the MMCR (Millimeter Wavelength Cloud Radar) derived cloud occurrence as a function of reflectivity (dBZ) for the composites of low and high large-scale lead flux are shown in Fig. 1a, c, respectively. Based on prior research ${ }^{25}$, clouds are generally associated with $\mathrm{dBZ}<-10$, while drizzle and light precipitation (heavy precipitation) correspond to $\mathrm{dBZ}$ between -10 and $10(\mathrm{dBZ} \geq 10)$. Current understanding ${ }^{16,20}$ suggests we would find more boundary layer clouds under high lead flux conditions, but we find just the opposite in our analyses. The curves in Fig. 1c show that for the high lead flux intervals, clouds within the boundary layer (i.e., $0-1 \mathrm{~km}$ ) with $\mathrm{dBZ}>-25$ are observed to have a frequency of $<10 \%$. However, for the low lead flux periods, up to $40 \%$ of the boundary layer clouds have $\mathrm{dBZ}>-25$ (Fig. 1a).

To investigate the robustness of this finding, we used the combined CloudSat-CALIPSO (Cloud-Aerosol Lidar and Infrared Pathfinder Satellite Observations) ${ }^{26,27}$ data to obtain profiles of cloud occurrence frequency in the region offshore within 200 $\mathrm{km}$ of Barrow and performed a similar analysis for the same composites of low and high lead flux intervals. The low-level cloud occurrence frequency (Supplementary Fig. 4) from CloudSat-CALIPSO over this region also decreases as the largescale lead flux increases. The consistency of lead and low cloud associations between the MMCR and CloudSat-CALIPSO cloud occurrence frequencies suggests that the low-level clouds detected by ground-based remote sensing at Barrow are also representative of the low-level clouds over the adjacent ocean when the wind is onshore and of moderate speed (see Methods).

The reliability of this unexpected result depends on effectively separating the effects of large-scale meteorology on the clouds and leads from the effects of leads on the low-level clouds. Therefore, we performed an analysis of the synoptic environments over a Barrow-centered region (Fig. 2) and pan-Arctic (Supplementary Fig. 5) for low and high lead flux periods, using hourly MERRA-2 (Modern-Era Retrospective analysis for Research and Applications version 2) reanalysis dataset ${ }^{28}$. The composite analyses for the low and high lead flux periods show similar patterns of geopotential height at each level (1000, 850, and $500 \mathrm{hPa}$ ). In both cases, a ridge tilts equatorward with height near Barrow and the adjacent ocean region, though it is slightly weaker in the composite of low lead flux intervals. The eastern flank of the ridge produces northerly wind for our study area. Overall, the two sets of periods have similar meteorological conditions, which minimizes the likelihood that the large-scale meteorology is significantly different between the two sets. The corresponding analysis using the NCEP-NCAR reanalysis produces results very similar to Fig. 2 (not shown). We also examined the meteorological conditions based on in-situ surface measurements at Barrow and the lead fractions that we used to calculate the large-scale lead fluxes (Supplementary Fig. 6). The 2$\mathrm{m}$ air temperature, $10-\mathrm{m}$ wind speed and wind direction have similar distributions in the high and low lead flux periods (Supplementary Fig. 6a-c, e-g). Among all the factors that contribute to the large-scale lead flux, it is found that lead fraction dominates the variations in large-scale lead flux, with a correlation of 0.9 (Supplementary Fig. 6d). This further demonstrates that meteorological conditions in both regimes resemble each other and cannot account for the differences between these two selected large-scale lead flux regimes.

Investigating the underlying mechanisms. The surprising observational results suggest some intriguing physical mechanisms. For example, the dearth of low-level clouds in the high leadflux case could reflect desiccation by precipitation or downmixing of dry air by lead-induced convection. Three-dimensional cloud-resolving simulations (see Methods) were conducted in an effort to understand the underlying physics. The simulated 
a

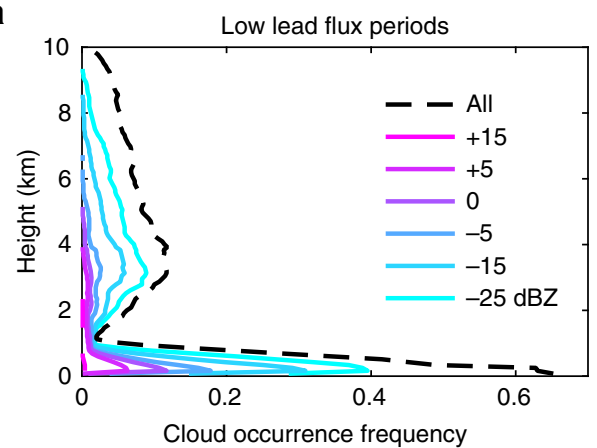

b

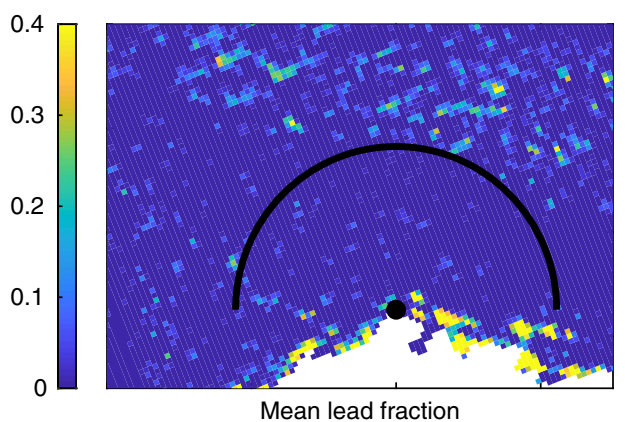

C

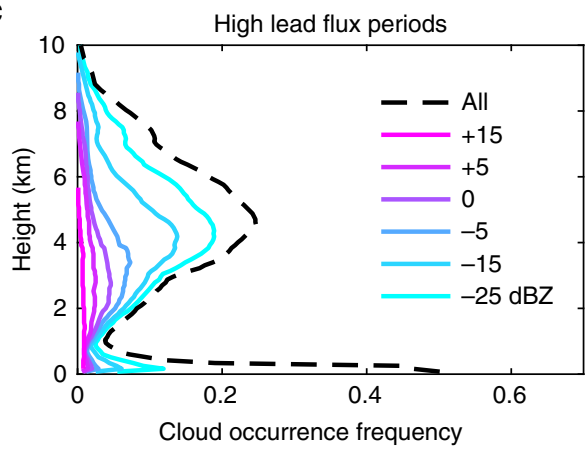

d

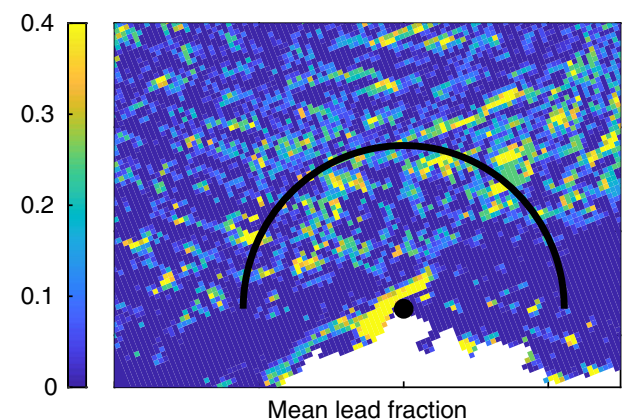

Fig. 1 MMCR derived cloud occurrence frequency and the corresponding mean lead fraction. a The vertical frequency distribution of cloud occurrence as a function of minimum reflectivity (dBZ) for the low lead flux periods. $\mathbf{b}$ Mean lead fraction based on AMSR-E data for four representative low lead flux periods in February 2011 (days 14, 15, 26, 27). c The same as a but for the high lead flux periods. d The same as b but for four representative high lead flux periods in February 2010 (days 19, 22, 23, 24). The coastal region of Alaska is shown in white, Barrow is indicated by a filled black circle, and the top of the $200-\mathrm{km}$ radius semicircle is directed north.
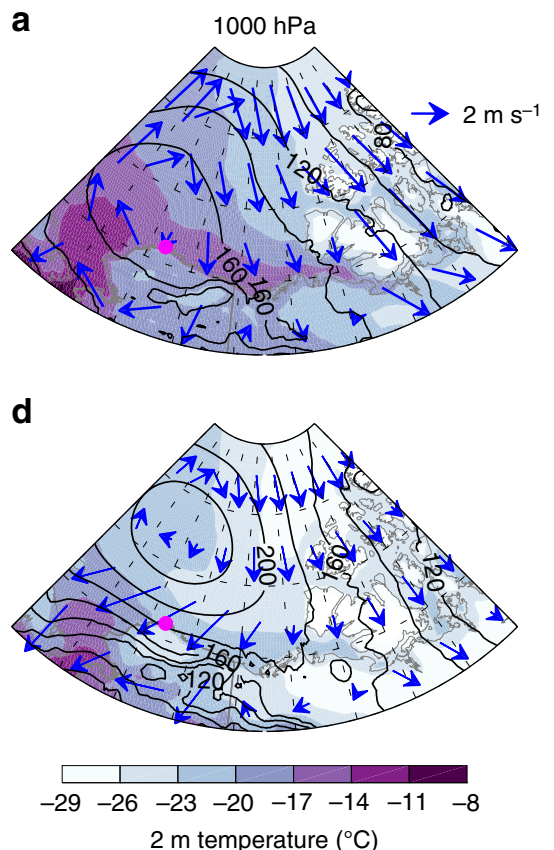

b

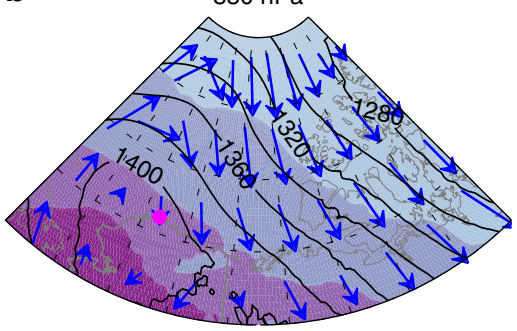

$\mathbf{e}$

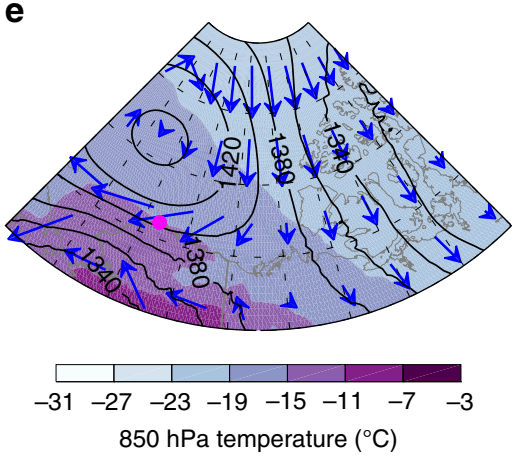

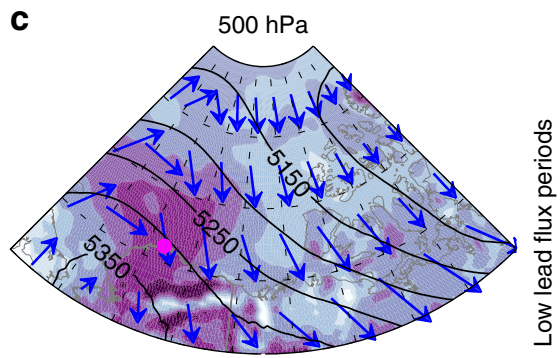

,

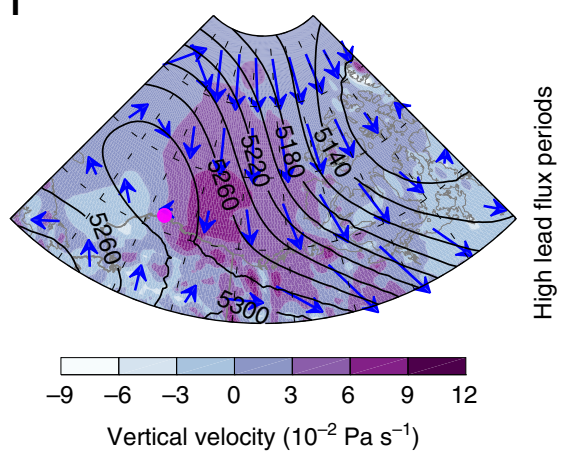

Fig. 2 Large-scale synoptic conditions. a-c Composites of geopotential height (black contours) and wind velocity (arrows) at 1000 hPa (wind is at $10 \mathrm{~m}$ ), 850 and $500 \mathrm{hPa}$ for the set of low lead flux periods. Color shading indicates 2-m air temperature, 850-hPa temperature, and vertical velocity, respectively. d-f The same as a-c but for the high lead flux periods. The domain is $65-85^{\circ} \mathrm{N}, 90-180^{\circ} \mathrm{W}$, and the Barrow site is indicated by the filled magenta circle.

boundary layer clouds from the four cases (i.e., OPEN, OPENOPEN, OPENFROZEN, and FROZENFROZEN, see Methods) are displayed in Figs. 3 and 4. The FROZENFROZEN case is not shown in Fig. 3 because no radiatively significant clouds are generated in this case, as shown in Fig. 4. The $x-z$ hydrometeor profiles (Fig. 3) illustrate the cloud evolution in each case, while the time series of cloud coverage (Fig. 4) further quantitatively indicates the differences of cloud amount between these cases. Here a threshold of $3.0 \mathrm{~g} \mathrm{~m}^{-2}$ is chosen in Figs. 3 and 4 as downwelling LW radiation is particularly sensitive to total water 
a
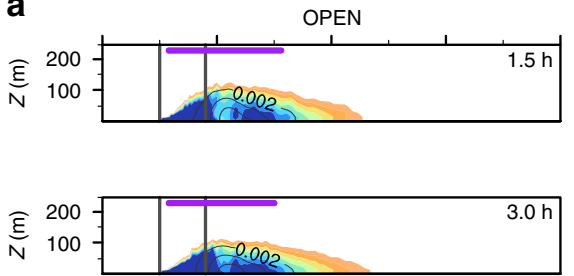

b
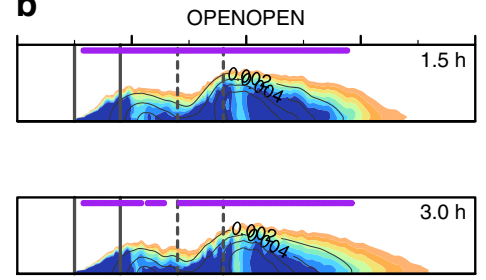

C
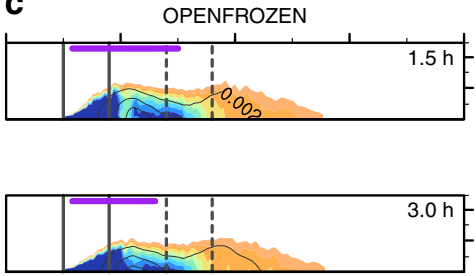
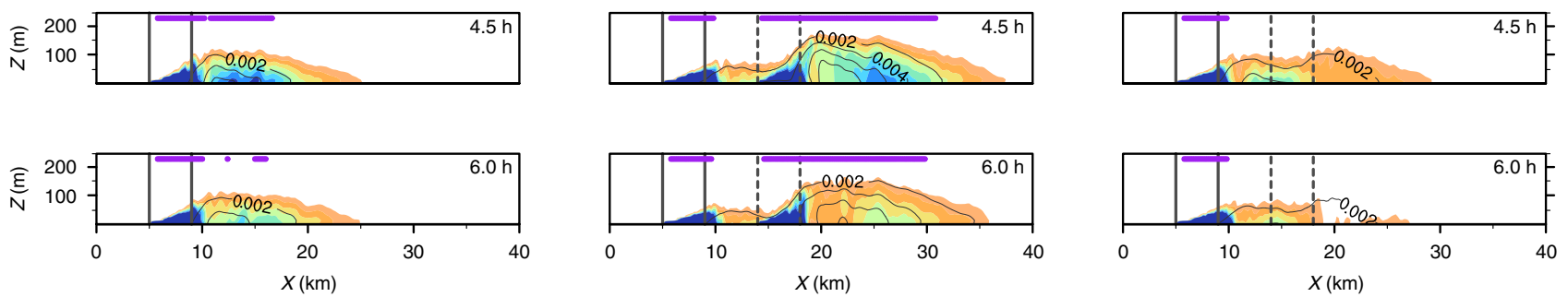

\begin{tabular}{|l|l|}
\hline & $\mid$ \\
\hline 0.01 & 0.012
\end{tabular}

0.014

Cloud condensate $\left(\mathrm{g} \mathrm{kg}^{-1}\right)$

Fig. 3 Evolution of the simulated clouds response to leads. a The $x-z$ profiles of the cloud condensate (cloud water plus cloud ice mixing ratio, shaded contour lines) and precipitating water (rain and snow, solid contour lines with intervals of $0.002 \mathrm{~g} \mathrm{~kg}^{-1}$ ) from the OPEN case. b-c The same as a but for the OPENOPEN and OPENFROZEN cases, respectively. For each case, four simulation times (1.5, 3.0, 4.5, and 6.0 hrs) are displayed. The purple bars near the top of the selected domain indicate the place where the clouds are radiatively significant, with a total water path greater than $3.0 \mathrm{~g}$ m -2 . All results are averaged along the $y$ direction. The upstream open lead extends from $x=5 \mathrm{~km}$ to $x=9 \mathrm{~km}$, as indicated by the two vertical solid lines in the domain, and the downstream open or frozen lead extends from $x=14 \mathrm{~km}$ to $x=19 \mathrm{~km}$, as indicated by the two vertical dashed lines. Note that the scales are different on the $x$ and $y$ axis.

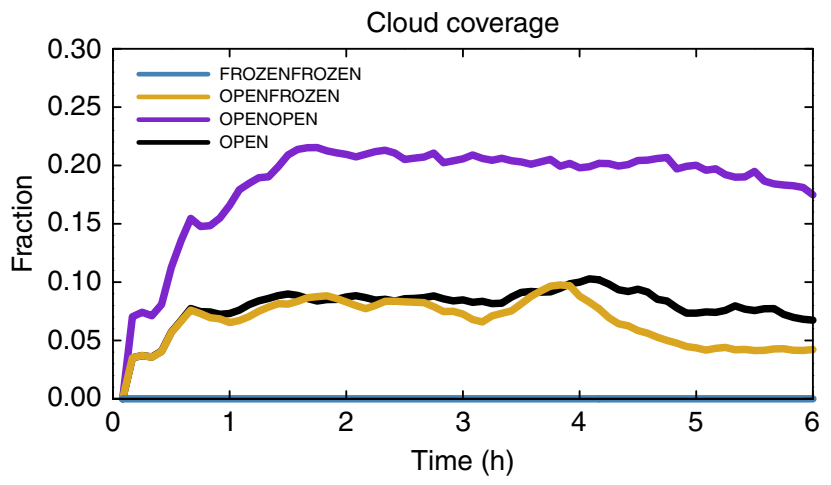

Fig. 4 Time series of cloud coverage. Time series of the cloud coverage from the OPEN (black), OPENOPEN (purple), OPENFROZEN (orange), and FROZENFROZEN (blue) cases. The cloud coverage is defined as the fraction of grid points with radiatively significant clouds for the entire domain.

path exceeding $3.0 \mathrm{~g} \mathrm{~m}^{-2}$, resulting in an increase in downwelling LW radiation by roughly $6 \mathrm{~W} \mathrm{~m}^{-2}$ compared to the initial condition. In both OPEN and OPENOPEN cases, extensive clouds are produced downstream of the lead (Fig. 3), which is consistent with previous studies ${ }^{16,20,22}$. A comparison of these two cases demonstrates that more boundary layer clouds are generated if the lead (completely ice-free) area fraction is doubled. The corresponding 6-h averaged cloud fraction is 0.185 in OPENOPEN versus 0.080 in OPEN (Fig. 4). This is what we expected based on current understanding. However, if the lead fraction is doubled but the added lead area is frozen (i.e., OPENFROZEN), lead-induced low clouds decrease to 0.066 (Fig. 4). At $6 \mathrm{~h}$, cloud coverage in the OPENFROZEN case is 0.042 , which is $37.3 \%$ less than that in the OPEN case. These differences of cloud fraction between the OPEN and OPENFROZEN cases are consistent with our observational analyses in which higher lead flux periods are associated with lower cloud occurrence frequencies, and also indicate that newly frozen leads tend to reduce the low-level clouds generated by an upstream open lead.

Because of the different thickness of ice between recently frozen leads and open leads $(5 \mathrm{~cm}$ versus $0 \mathrm{~cm}$ in our simulations), the surface fluxes may change significantly. We analyzed the changes of surface fluxes to understand why a recently frozen lead can have such a significant impact on the evolution of clouds. To emphasize the impacts of leads on the surface energy budget, all the energy exchange components were averaged over the lead area (Fig. 5). As a comparison, over the thick ice surface (i.e., -6 to $0 \mathrm{~h}$ ), we find longwave radiative fluxes dominate the surface heat exchange, with turbulent latent heat (LH) and sensible heat (SH) fluxes being close to zero. Over the open lead area, all the energy fluxes are significantly increased to different extents (Fig. 5a-c). Specifically, the 6-h averaged LH and SH in the OPEN case increase to 100 and $357 \mathrm{~W} \mathrm{~m}^{-2}$, respectively. The magnitudes of the counterparts over open leads in OPEN, OPENOPEN and OPENFROZEN cases are quite similar. However, these surface fluxes change in different ways over the frozen leads in OPENFROZEN and FROZENFROZEN. Comparing the turbulent fluxes over downstream frozen lead to upstream open lead in OPENFROZEN (Fig. 5c), we find that LH decreases sharply by $69 \%$ to $31 \mathrm{~W} \mathrm{~m}^{-2}$ due to the exponential dependence of the saturation vapor pressure upon temperature, while less reduction occurs in $\mathrm{SH}$ (decreased by roughly $35.8 \%$ to $228 \mathrm{~W} \mathrm{~m}^{-2}$ ). The differences in turbulent fluxes over open leads and frozen leads suggest that the turbulent fluxes ( $\mathrm{SH}$ and $\mathrm{LH}$ ) over the newly frozen leads play a key role in dissipating low-level clouds.

Changes of the 2D PDFs of the thermodynamic state characterized by liquid-ice static energy and total water mixing ratio from the OPEN case to the other three cases are displayed in Fig. 6. The corresponding PDFs for each case are shown in 
a

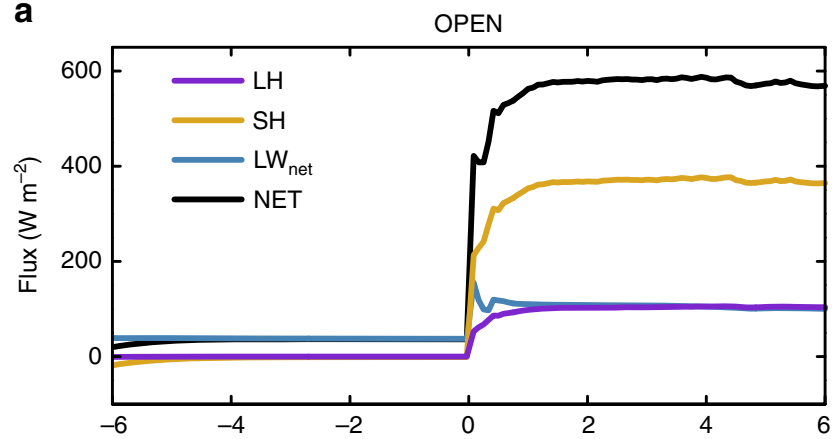

C

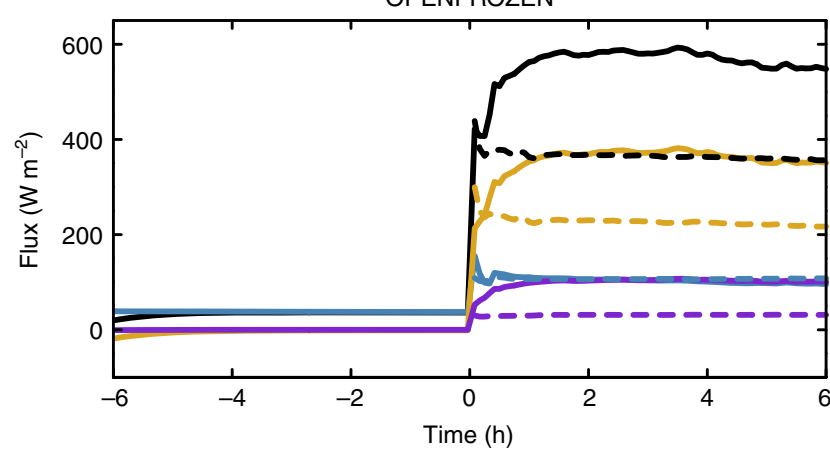

b

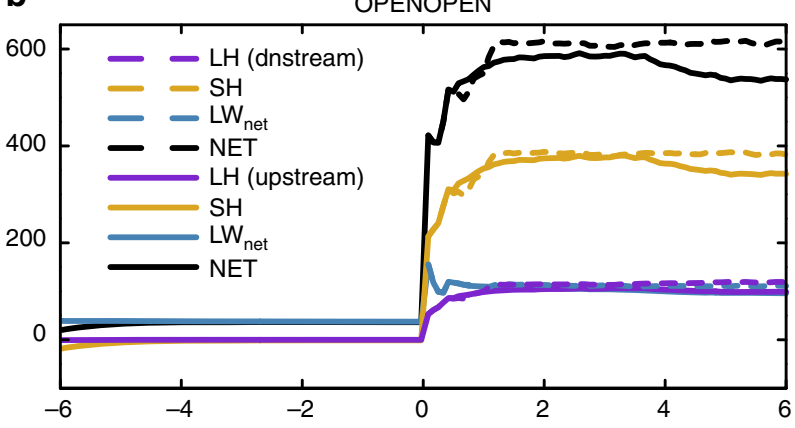

d

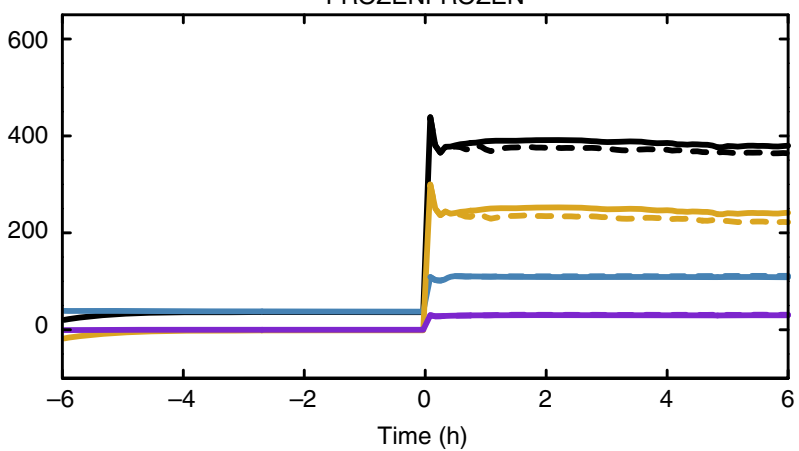

Fig. 5 Time series of the surface fluxes averaged over lead area. a Time series of surface latent heat flux (LH), sensible heat flux (SH), net longwave radiative flux $\left(L W_{\text {net }}\right)$, and the net total flux (NET) averaged over the lead area from the OPEN case. NET excludes conductive heat flux at the top layer, and upward flux is defined as positive. $\mathbf{b}$ The same as $\mathbf{a}$ but for the OPENOPEN case. Solid curves indicate the fluxes averaged over the upstream open lead while dashed lines indicate the fluxes averaged over the downstream open lead. $\mathbf{c}$ The same as $\mathbf{b}$ but for the OPENFROZEN case with an upstream open lead (solid lines) and a downstream frozen lead (dashed lines). $\mathbf{d}$ The same as $\mathbf{b}$ but for the FROZENFROZEN case.
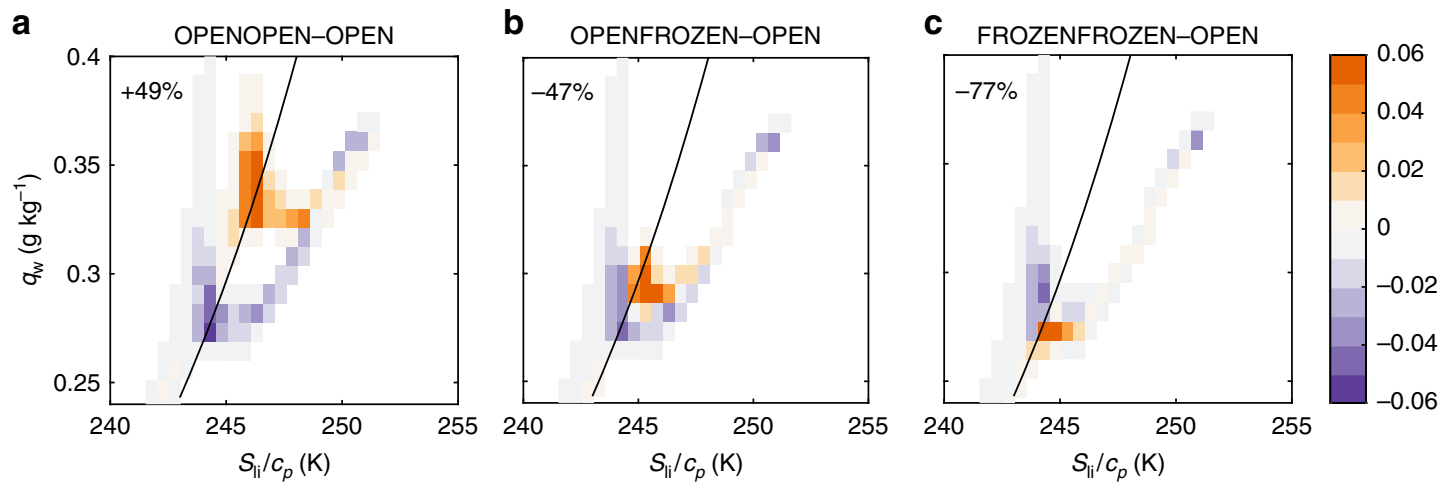

Fig. 6 Mixing diagram of the difference between high and low lead fraction cases. a Differences of PDFs of thermodynamic state characterized by liquidice static energy $\left(S_{\mid l} / c_{p}\right)$ and total water mixing ratio $\left(q_{w}\right.$ sum of the water vapor, cloud water, and cloud ice) between OPENOPEN and OPEN. Plotted results are from the last two simulation hours for all model grid volumes within a selected domain with $x$ extending from 20 to $30 \mathrm{~km}$ and $z$ extending from the bottom level to $300 \mathrm{~m}$, where most clouds occur. The solid black line indicates the theoretical cloudy-clear boundary line, with cloud ice mixing ratio equal to $0.01 \mathrm{~g} \mathrm{~kg}^{-1}$. b The same as a but for differences between OPENFROZEN and OPEN case PDFs. $\mathbf{c}$ The same as a but for differences between FROZENFROZEN and OPEN case PDFs. In the OPEN case, $x$ extends from 10 to $20 \mathrm{~km}$. The percentages on the top left are the percentage changes of cloudy volume fraction from the OPEN case to the other three cases.

Supplementary Fig. 7. Results are from a $10 \mathrm{~km}$ by $12.8 \mathrm{~km}$ by $300 \mathrm{~m}$ domain with grid volumes of $200 \mathrm{~m}$ by $200 \mathrm{~m}$ by $12 \mathrm{~m}$. We sampled the simulation results every $5 \mathrm{~min}$, and calculated the PDF of each thermodynamic state bin for the last two hours. The PDF difference indicates an $\sim 49 \%$ increase in the cloud volume fraction from the OPEN to OPENOPEN cases (Fig. 6a), owing to the shift of a large number of grid volumes to a larger total water mixing ratio and larger liquid-ice static energy from below to above the cloudy-clear boundary (black curve). This is caused by the large vertical turbulent temperature flux (Supplementary
Fig. 8) and water vapor flux (Supplementary Fig. 10) over the two open leads in the OPENOPEN case. However, the fraction of cloudy grid volumes decreases by $47 \%$ from OPEN to OPENFROZEN. While a large number of grid volumes shift to a higher liquid-ice static energy, increases in total water mixing ratio are not sufficient to maintain all of the previously cloudy grid volumes (Fig. 6b). The reduced water vapor supply (Supplementary Figs. 10, 11) as well as the relatively large temperature flux (Supplementary Figs. 8, 9) over the frozen lead, which provides the necessary buoyancy for convection and entrainment of warm 
air, might play a central role in reducing the relative humidity and thus dissipating these low clouds. As for the difference between FROZENFROZEN and OPEN (Fig. 6c), almost all the previously cloudy grid volumes in the OPEN case are shifted downward and below the cloudy-clear border due to the reduced water vapor flux, which is consistent with the zero cloud coverage shown in Fig. 4. Our model simulation results provide a plausible explanation for the counterintuitive observational results: instead of including a larger fraction of completely open leads, the observed high lead fraction must largely consist of newly frozen leads which tend to reduce any pre-existing low-level cloudiness.

\section{Discussion}

Our observational analyses indicate an unexpected lead-low cloud association and our numerical experiments show supporting results, that a region with an observed high lead fraction likely contains many newly frozen leads with ice thickness ranging from roughly $2.5 \mathrm{~cm}$ up to $30 \mathrm{~cm}$, which largely suppress the latent heat flux with lesser impact on the sensible heat flux ${ }^{29}$ and consequently tend to dissipate boundary layer clouds (Supplementary Figs. 12 and 13). This explanation is reasonable given that open leads usually freeze over after remaining open for just a few hours and thinner ice generally grows faster than thicker ice. Consider a scenario in which no low-level clouds and no leads exist initially, after which leads open and produce low-level clouds. As new leads keep opening and then freezing, the recently frozen lead area will increase, which contributes to an increasing total detected lead area (e.g., Advanced Microwave Scanning Radiometer for EOS (AMSR-E) detected lead fraction). Because the accumulated newly frozen leads tend to dissipate low-level clouds, the large detected lead fraction is accompanied with fewer low clouds. As shown in Fig. 3, the cloudiness between an upstream open lead and a downstream open or frozen lead is decreased. Additionally, doubling the open lead fraction from OPEN to OPENOPEN does not necessarily double the cloud coverage (i.e., the increase is nonlinear, Fig. 4). These results indicate potentially important lead-lead interactions which will be further examined in our future work. We further compared the surface energy fluxes, averaged over the thick ice surface and within half of the entire domain ( $x=0$ to $x=51.2 \mathrm{~km}$ ), from the OPENOPEN and OPENFROZEN cases, and find that with a lead fraction of $15.6 \%$, freezing half the lead area and the consequent dissipation of lowlevel clouds could result in an increase in energy loss from the thick sea ice by $\sim 1.6 \mathrm{~W} \mathrm{~m}^{-2}$. The entire domain averaged surface fluxes in each case (Supplementary Fig. 14) indicate the impacts of the different lead scenarios on the large-scale surface energy budget, compared to the NOLEAD case. These preliminary findings stress the importance of differentiating open water leads from recently frozen leads, though our simulated cloud coverage is less than that observed owing to the idealized configurations (e.g., invariable lead fraction, periodic boundary layer conditions, and neglect of moisture advection). Future work will pursue such differentiation and will also examine the effects of lead modulation of low-level clouds on the lead-atmosphere feedbacks and the large-scale surface heat balance over the pan-Arctic.

As mentioned above, besides the local surface-based process (i.e., lead fraction change), the large-scale meteorology may also have impacts on the low-level clouds, such as the temperature and humidity advection by the large-scale synoptic flow ${ }^{30-33}$. An analysis of 11 years of observations at NSA (North Slope of Alaska) ${ }^{34}$ showed that distinct synoptic-scale and mesoscale meteorology regimes produce distinct cloud states. For example, high pressure over the Beaufort Sea and the Arctic Ocean with northerly cold, dry anticyclonic flow causes fairly small cloud occurrence frequencies at all levels, while cyclonic flow around
Aleutian low pressure systems leads to large cloud occurrence frequencies throughout the column by advecting warm, moist air through the Bering Strait. In our study, the Barrow radiosonde data and surface measurements were used to select two categories with similar atmospheric states, so that the influences of leads on the low-level clouds dominate. However, the reader should bear in mind that a role of the large-scale synoptic conditions in cloudiness cannot be excluded with great certainty, to which the slight difference between the cloud occurrence frequency in high levels above the boundary layer (Fig. 1a, c) may in part be related. Determining the relative roles of large-scale meteorology and large-scale lead fluxes in determining the distribution of low-level clouds will be addressed in our future studies. The modeling study demonstrates that recently frozen leads with a certain range of ice thickness tend to dissipate low clouds produced by open leads. It is hypothesized that both the suppressed water vapor supply and the strong convection induced by the large sensible heat flux provide favorable conditions for the dissipation of the clouds. Details of the processes that determine how low clouds are reduced by frozen leads, such as entrainment of warm air owing to the lead-induced convective plumes, will be further examined in future work.

\section{Methods}

Data and algorithm. In this study, we focus on an Arctic region offshore within $200 \mathrm{~km}$ of Barrow because of the relatively long-time record of Arctic clouds collected at Barrow, the NSA's main research site, by the Atmospheric Radiation Measurement (ARM) $)^{35}$ program. The datasets used for the observational analyses are summarized in Supplementary Table 1. Observations for the months of January-April and November-December for the years 2008-2011 were chosen because of the availability of reliable data. For the present analyses, control for meteorological conditions, including large-scale flow regime, is a potential challenge which we address by using a conditional sampling algorithm (described below) as well as examining the large-scale synoptic pattern from reanalyses. Using the twelve-hourly radiosondes and hourly surface measurements ${ }^{36}$ at Barrow along with the daily lead fractions from the AMSR-E $\mathrm{E}^{37}$, we first selected two subsets of the 12-h time intervals (centered at hour 6 or 18) that have similar atmospheric states at Barrow and over the adjacent ocean except for the large-scale turbulent sensible heat flux due to the leads. Then we compared the cloud occurrence frequency profiles for these two subsets using the NSA MMCR ${ }^{38}$ data at Barrow.

Specifically, we first calculated three quantities for all 12-h periods for which the needed data were available: dry fraction is the fraction of the atmosphere below $2000 \mathrm{~m}$ above ground level with relative humidity $<50 \%$ at Barrow; turbulent surface flux from leads is the turbulent surface sensible heat flux per unit area over leads calculated from surface temperature of water (i.e., $-2{ }^{\circ} \mathrm{C}$ ), air temperature, surface pressure, relative humidity, and wind speed at Barrow following the previous work ${ }^{39,40}$; large-scale turbulent surface flux due to leads is the turbulent surface sensible heat flux from leads multiplied by the lead fraction (i.e., "large-scale turbulent sensible heat flux"). The lead fraction was derived from the AMSR-E lead area fraction for the Arctic dataset ${ }^{37}$ by averaging values within the semicircle north of Barrow (Fig. 1b). The AMSR-E lead detection method ${ }^{37}$ produces a lead area fraction which is the sum of open leads and those with thin ice cover by using the ratio of brightness temperatures observed at $89-19 \mathrm{GHz}$. Therefore, both open water leads and thin-ice-covered leads are included in the lead fraction.

All 12-h intervals were then conditionally sampled based on the following three criteria: a dry fraction $>0.42$ to avoid deep cloud layers that could make lead modulation of cloudiness difficult to detect, a wind direction between $240^{\circ}$ and $110^{\circ}$ (clockwise) to select trajectories that are from the ocean and over leads when

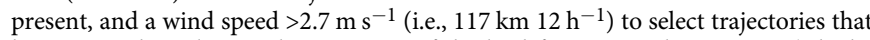
have crossed a substantial proportion of the lead-fraction-analysis region (which extends $200 \mathrm{~km}$ from Barrow) during the 12-h analysis period.

From the set of all available 12-h intervals that met these three criteria, two subsets were chosen: one with the component of large-scale turbulent sensible heat flux due to leads in the upper third of all such values ("high lead flux regime," with large-scale flux $>8 \mathrm{~W} \mathrm{~m}^{-2}$ ) and the other with this flux in the lower third of all such values ("low lead flux regime," with large-scale flux $<3.8 \mathrm{~W} \mathrm{~m}^{-2}$ ). A total of 91 samples $(8.0 \%)$ were included for high lead flux intervals and $31(2.6 \%)$ for the low lead flux intervals. Finally, the cloud occurrence frequency profiles were calculated for the two subsets using NSA MMCR data, processed with quality control and masking following the previous study ${ }^{41}$, to determine the statistical associations between large-scale lead flux and low-level cloud occurrence. The leadlow cloud associations were further examined using satellite data (offshore within $200 \mathrm{~km}$ of Barrow) from the CloudSat Cloud Profiling Radar (CPR) ${ }^{26}$ combined with CALIPSO lidar ${ }^{27}$. To characterize the large-scale synoptic environment for the two subsets, we used both the hourly MERRA- $2^{28}$ and the six-hourly NCEP 
(National Centers for Environmental Prediction)-NCAR (National Center for Atmospheric Research) atmospheric reanalysis ${ }^{42}$.

Model and experiment design. The model we used is the System for Atmospheric Modeling, version 6.11 (SAM) ${ }^{43}$, which is a three-dimensional, nonhydrostatic, cloud-resolving model. SAM employs appropriate physical parameterizations for subgrid-scale processes and is well-suited for simulating boundary layer clouds ${ }^{44-}$ 46. The infrared radiative fluxes interact with clouds and the surface as well as the atmosphere and provide radiative heating rates. The subgrid-scale turbulence closure employs a first-order Smagorinsky closure scheme in which the stability is accounted for in the levels above the surface layer; the surface turbulent fluxes are estimated using Monin-Obukhov similarity ${ }^{47}$ and more details about the integral forms of stability functions used in the Monin-Obukhov similarity are shown in the Supplementary Information. We used a two-moment ice-phase microphysics parameterization ${ }^{48}$. The horizontal domain size in our study is $102.4 \mathrm{~km}$ by 12.8 $\mathrm{km}$ with a horizontal grid spacing of $200 \mathrm{~m}$. In addition, the model has 81 levels in the vertical direction with the model top at about $1.5 \mathrm{~km}$, which is high enough to simulate the Arctic boundary layer. The vertical grid size is variable, with a minimum size of $12 \mathrm{~m}$ at the surface and an average size of $18 \mathrm{~m}$. SAM uses periodic lateral boundaries, and a rigid lid at the top of the domain.

The Simplified Land Model (SLM) ${ }^{49}$ is coupled to SAM version 6.11 and is used to represent land-atmosphere interactions. SLM currently has 17 land surface types, including water and snow/ice. To simulate a recently frozen lead, we added a new land type, which is a $5-\mathrm{cm}$ layer of ice covering open water. A land type index in each surface grid point automatically defines the parameters of the vegetation and soil. We set up a horizontally inhomogeneous surface with different land types to simulate the Arctic sea ice with leads. SLM also has an interactive soil model, currently with nine layers. We therefore used nine layers in the sea ice. For simplification, no snow is included in the present study. The vertical ice layer thickness is prescribed for each surface type, and the initial temperature profile is the equilibrium profile for the initial atmospheric conditions. In the SLM, the surface temperature of the ice evolves in response to the surface energy balance.

Because the AMSR-E lead area fraction includes both open leads and newly frozen leads, we designed a series of simulations to investigate the possible impacts of frozen leads on the boundary layer clouds. We began with a "NOLEAD" case (simulation) where the entire domain was covered by a single sea ice land type with a thickness of $1.995 \mathrm{~m}$. This simulation was conducted and run for $6 \mathrm{~h}(-6$ to $0 \mathrm{~h}$ ) to ensure that the atmosphere and sea ice reached an equilibrium state. Then, corresponding to our observational analyses with different lead fractions, we performed simulations for four different lead configurations, where all leads are $4 \mathrm{~km}$ wide: an "OPEN" case in which a single lead was opened in the domain to investigate the effects caused by the presence of the open lead, an "OPENOPEN" case which modifies the OPEN case by adding another identical open lead $5 \mathrm{~km}$ downstream, an "OPENFROZEN" case which modifies the OPEN case by adding an identical but frozen lead $5 \mathrm{~km}$ downstream, and a "FROZENFROZEN" case which modifies the OPENFROZEN case by having both leads be frozen. The lead area fraction doubled from the OPEN case to the other three cases, but with different frozen lead proportion (i.e., $0 \%, 50 \%$, and $100 \%$ in the OPENOPEN, OPENFROZEN, and FROZENFROZEN, respectively), which allows us to examine the potential impacts of frozen leads as well as lead fraction on the low clouds. All four cases were run for $6 \mathrm{~h}(0-6 \mathrm{~h})$. Initial conditions were based on the Surface Heat Budget of the Arctic (SHEBA) project following previous work ${ }^{8}$, with the large-scale wind direction approximately perpendicular to the lead orientation. Here ensemble simulations with slightly different variation in initial conditions are not considered because the simulated flow is strongly forced by fluxes from leads instead of variability associated with initial conditions

\section{Data availability}

The authors declare that the observational and reanalysis data supporting the findings of this study are available within the paper and its supplementary information file. Data from our model simulations are available upon request.

\section{Code availability}

The codes used to generate these results are available upon request.

Received: 29 November 2018; Accepted: 16 December 2019; Published online: 10 January 2020

\section{References}

1. Smith, S. D., Muench, R. D. \& Pease, C. H. Polynyas and leads: an overview of physical processes and environment. J. Geophys. Res. 95, 9461-9479 (1990).

2. Andreas, E. L. Estimation of heat and mass fluxes over Arctic leads. Mon. Wea. Rev. 108, 2057-2063 (1980).

3. Vowinckel, E. \& Orvig, S. The heat and water budgets of a beaver pond. Atmosphere 11, 166-178 (1973).
4. Maykut, G. A. Energy exchange over young sea ice in the central Arctic. J. Geophys. Res. 83, 3646-368 (1978).

5. Ledley, T. S. For a lead-temperature feedback in climatic variation. Geophys. Res. Lett. 15, 36-39 (1988).

6. Kay, J. E. \& Gettelman, A. Cloud influence on and response to seasonal Arctic sea ice loss. J. Geophys. Res. 114, D18204 (2009).

7. Schnell, R. C. et al. Lidar detection of leads in Arctic sea ice. Nature 339, 530-532 (1989).

8. Zulauf, M. A. \& Krueger, S. K. Two-dimensional cloud-resolving modeling of the atmospheric effects of Arctic leads based upon midwinter conditions at the Surface Heat Budget of the Arctic Ocean ice camp. J. Geophys. Res. 108, 4312 (2003).

9. Intrieri, J. M., Shupe, M. D., Uttal, T. \& McCarty, B. J. An annual cycle of Arctic surface cloud forcing at SHEBA. J. Geophys. Res. Atmos. 107, 8030 (2002).

10. Curry, J. A., Schramm, J. L. \& Ebert, E. E. Impact of clouds on the surface radiation balance of the Arctic Ocean. Meteor. Atmos. Phys. 51, 197-217 (1993).

11. Pinto, J. O. \& Curry, J. A. Atmospheric convective plumes emanating from leads 2. microphysical and radiative processes. J. Geophys. Res. 100, 4633-4642 (1995).

12. Maslanik, J., Stroeve, J., Fowler, C. \& Emery, W. Distribution and trends in Arctic sea ice age through spring 2011. Geophys. Res. Lett. 38, L13502 (2011).

13. Hakkinen, S., Proshutinsky, A. \& Ashik, I. Sea ice drift in the Arctic since the 1950s. Geophys. Res. Lett. 35, L19704 (2008).

14. Rampal, P., Weiss, J. \& Marsan, D. Positive trend in the mean speed and deformation rate of Arctic sea ice, 1979-2007. J. Geophys. Res. Oceans 114, C05013 (2009).

15. Strong, C. \& Rigor, I. G. Arctic marginal ice zone trending wider in summer and narrower in winter. Geophys. Res. Lett. 40, 4864-4868 (2013).

16. Glendening, J. W. \& Burk, S. D. Turbulent transport from an Arctic lead: a large-eddy simulation. Boundary-Layer Meteor. 59, 315-339 (1992).

17. Pinto, J. O., Curry, J. A. \& Mcinnes, K. L. Atmospheric convective plumes emanating from leads 1. thermodynamic structure. J. Geophys. Res. Oceans 100, 4621-4631 (1995).

18. Burk, S. D., Fett, R. W. \& Englebretson, R. E. Numerical simulation of cloud plumes emanating from Arctic leads. J. Geophys. Res. Atmos. 102, 16529-16544 (1997).

19. Weinbrecht, S. \& Raasch, S. High-resolution simulations of the turbulent flow in the vicinity of an Arctic lead. J. Geophys. Res. Oceans 106, 27035-27046 (2001).

20. Zulauf, M. A. \& Krueger, S. K. Two-dimensional numerical simulations of Arctic leads: Plume penetration height. J. Geophys. Res. Oceans 108, 8050 (2003).

21. Esau, I. N. Amplification of turbulent exchange over wide Arctic leads: largeeddy simulation study. J. Geophys. Res. Atmos 112, D08109 (2007).

22. Lüpkes, C. et al. Modeling convection over arctic leads with LES and a noneddy-resolving microscale model. J. Geophys. Res. Oceans 113, C09028 (2008).

23. Chechin, D. G., Makhotina, I. A., Lüpkes, C. \& Makshtas, A. P. Effect of wind speed and leads on clear-sky cooling over Arctic sea ice during polar night. J. Atmos. Sci. 76, 2481-2503 (2019).

24. Shupe, M. D. et al. Clouds at Arctic atmospheric observatories. Part I: occurrence and macrophysical properties. J. Appl. Meteor. Climatol. 50, 626-644 (2011)

25. Zhao, W., Marchand, R. \& Fu, Q. The diurnal cycle of clouds and precipitation at the ARM SGP site: cloud radar observations and simulations from the multiscale modeling framework. J. Geophys. Res. Atmos. 122, 7519-7536 (2017)

26. Marchand, R., Mace, G. G., Ackerman, T. \& Stephens, G. Hydrometeor detection using Cloudsat-an earth-orbiting $94-\mathrm{GHz}$ cloud radar. J. Atmos. Oceanic Technol. 25, 519-533 (2008).

27. Mace, G. G. \& Zhang, Q. The CloudSat radar-lidar geometrical profile product (RL-GeoProf): updates, improvements, and selected results. J. Geophys. Res. Atmos. 119, 9441-9462 (2014).

28. Gelaro, R. et al. The modern-era retrospective analysis for research and applications, version 2 (MERRA-2). J. Clim. 30, 5419-5454 (2017).

29. Tetzlaff, A., Lüpkes, C. \& Hartmann, J. Aircraft-based observations of atmospheric boundary-layer modification over Arctic leads. Q. J. R. Meteorol. Soc. 141, 2839-2856 (2015).

30. Curry, J. A. \& Herman, G. F. Relationships between large-scale heat and moisture budgets and the occurrence of Arctic stratus clouds. Mon. Weather Rev. 113, 1441-1457 (1985)

31. Sheu, R. S. \& Curry, J. A. Interactions between north Atlantic clouds and the large-scale environment. Mon. Weather Rev. 120, 261-278 (1992).

32. Barton, N. P., Klein, S. A., Boyle, J. S. \& Zhang, Y. Y. Arctic synoptic regimes: comparing domain-wide Arctic cloud observations with CAM4 and CAM5 during similar dynamics. J. Geophys. Res. 117, D15205 (2012). 
33. Shupe, M. D. et al. Cloud and boundary layer interactions over the Arctic seaice in late summer. Atmos. Chem. Phys. 13, 13191-13244 (2013).

34. Mülmenstädt, J., Lubin, D., Russell, L. M. \& Vogelmann, A. M. Cloud properties over the North Slope of Alaska: identifying the prevailing meteorological regimes. J. Clim. 25, 8238-8258 (2012).

35. Stokes, G. M. \& Schwartz, S. E. The atmospheric radiation measurement (ARM) program: programmatic background and design of the cloud and radiation test bed. Bull. Amer. Meteor. Soc. 75, 1201-1221 (1994).

36. Herbert, G. A. et al. Control and monitoring instrumentation for the continuous measurement of atmospheric $\mathrm{CO} 2$ and meteorological variables. J. Atmos. Oceanic Technol. 3, 414-421 (1986).

37. Röhrs, J., Kaleschke, L., Bröhan, D. \& Siligam, P. K. An algorithm to detect sea ice leads by using AMSR-E passive microwave imagery. The Cryosphere $\mathbf{6}$, 343-352 (2012).

38. Clothiaux, E. E. et al. The atmospheric radiation measurement program cloud radars: operational modes. J. Atmos. Oceanic Technol. 16, 819-827 (1999).

39. Andreas, E. L. \& Cash, B. A. Convective heat transfer over wintertime leads and polynyas. J. Geophys. Res. Oceans 104, 25721-25734 (1999).

40. Marcq, S. \& Weiss, J. Influence of sea ice lead-width distribution on turbulent heat transfer between the ocean and the atmosphere. The Cryosphere 6, 143-156 (2012).

41. Mace, G. G. et al. Cloud radiative forcing at the atmospheric radiation measurement program climate research facility: 1 . technique, validation, and comparison to satellite-derived diagnostic quantities. J. Geophys. Res. Atmos. 111, D11S90 (2006).

42. Kalnay, E. et al. The NCEP/NCAR 40-year reanalysis project. Bull. Amer. Meteor. Soc. 77, 437-471 (1996).

43. Khairoutdinov, M. F. \& Randall, D. A. Cloud resolving modeling of the ARM summer 1997 IOP: model formulation, results, uncertainties, and sensitivities. J. Atmos. Sci. 60, 607-625 (2003).

44. Morrison, H., Zuidema, P., Ackerman, A. S., Avramov, A. \& Boer, G. D. Intercomparison of cloud model simulations of Arctic mixed-phase boundary layer clouds observed during SHEBA. J. Adv. Model. Earth Syst. 3, M06003 (2011).

45. Fletcher, J. K., Bretherton, C. S., Xiao, H., Sun, R. \& Han, J. Improving subtropical boundary layer cloudiness in the 2011 NCEP GFS. Geosci. Model Dev. 7, 2107-2120 (2014).

46. Yang, D. Boundary layer height and buoyancy determine the horizontal scale of convective self-aggregation. J. Atmos. Sci. 75, 469-478 (2018).

47. Obukhov, A. M. Turbulence in an atmosphere with a non-uniform temperature. Boundary-Layer Meteor. 2, 7-29 (1971).

48. Morrison, H., Curry, J. A. \& Khvorostyanov, V. I. A new double-moment microphysics parameterization for application in cloud and climate models. Part II: single-column modeling of Arctic clouds. J. Atmos. Sci. 62, 1665-1677 (2005).

49. Lee, J. M. \& Khairoutdinov, M. A simplified land model (SLM) for use in cloud-resolving models: formulation and evaluation. J. Adv. Model. Earth Syst. 7, 1368-1392 (2015).

\section{Acknowledgements}

This work is supported by the NASA grants 80NSSC18K0843, NNX13AQ34G, NNX10AM42G, NNX15AK17G, and NNX13A169G. X.L. is also supported by the Future Investigators in NASA Earth and Space Science and Technology (FINESST) fellowship through Grant 80NSSC19K1354. We would like to acknowledge the ARM user facility, a U.S. Department of Energy office of science user facility managed by the office of Biological and Environmental Research, for providing the radiosonde data. We also would like to thank Marat Khairoutdinov for the SAM support.

\section{Author contributions}

X.L., S.K., C.S., G.M. and S.B. conceived the project and contributed to writing. X.L. and S.B. performed the analysis of the observations and reanalysis products. X.L. conducted the modeling experiments and performed the analysis of experimental data.

\section{Competing interests}

The authors declare no competing interests.

\section{Additional information}

Supplementary information is available for this paper at https://doi.org/10.1038/s41467019-14074-5.

Correspondence and requests for materials should be addressed to X.L.

Peer review information Nature Communications thanks Christof Lüpkes and the other, anonymous, reviewer(s) for their contribution to the peer review of this work.

Reprints and permission information is available at http://www.nature.com/reprints

Publisher's note Springer Nature remains neutral with regard to jurisdictional claims in published maps and institutional affiliations.

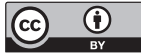

Open Access This article is licensed under a Creative Commons Attribution 4.0 International License, which permits use, sharing, adaptation, distribution and reproduction in any medium or format, as long as you give appropriate credit to the original author(s) and the source, provide a link to the Creative Commons license, and indicate if changes were made. The images or other third party material in this article are included in the article's Creative Commons license, unless indicated otherwise in a credit line to the material. If material is not included in the article's Creative Commons license and your intended use is not permitted by statutory regulation or exceeds the permitted use, you will need to obtain permission directly from the copyright holder. To view a copy of this license, visit http://creativecommons.org/ licenses/by/4.0/.

(๑) The Author(s) 2020 